University of St. Thomas, Minnesota

UST Research Online

2008

\title{
Advancing Administrative Supports for Research Development
}

K. Briar-Lawson

William Korr

B. White

P. Vroom

J. Zabora

See next page for additional authors

Follow this and additional works at: https://ir.stthomas.edu/ssw_pub

Part of the Clinical and Medical Social Work Commons, and the Social Work Commons

This Article is brought to you for free and open access by the School of Social Work at UST Research Online. It has been accepted for inclusion in Social Work Faculty/Staff Publications by an authorized administrator of UST

Research Online. For more information, please contact asle4660@stthomas.edu. 


\section{Author}

K. Briar-Lawson, William Korr, B. White, P. Vroom, J. Zabora, J. Middleton, Barbara W. Shank, and M. Schatz

This article is available at UST Research Online: https://ir.stthomas.edu/ssw_pub/14 


\section{Advancing Administrative Supports for Research Development}

\section{Briar-Lawson, K., Korr, W., White, B., Vroom, P., Zabora, J., Middleton, J., Shank, B. \& Schatz, M. (2008) Social Work Research, 32 (4), 236-241.}

Research intensive universities have raised the bar for all academic units, expecting them to increase research grants and contracts to support knowledge creation and scholarship. Similarly, performance requirements for faculty have changed, with annual reviews and tenure and promotion decisions weighting obtaining grants along with publication of scholarly products, teaching effectiveness, and service to the school, university and community. These expectations compel Deans and Directors of schools of social work to undertake new roles related to research development and administrative capacity building in order to help faculty and their units succeed.

Social work schools and departments must stay or become strategically positioned in their university or college, even as the context for research development has been dramatically altered as colleges and universities invest in the nanosciences or biotechnology rather than the social sciences. A $\$ 4$ billion nanoscience operation dwarfs the $\$ 20$ million that a robust research enterprise that a few schools of social work enjoy.

This paper highlights some of the opportunities, barriers, challenges, as well as stepping stones to success in the process of building research supports and infrastructures. Drawing upon presentations at recent meetings of the National Association of Deans and Directors of Schools of Social Work (NADD) that have been organized by the Institute of Social Work Research (IASWR), we feature several examples of approaches advancing supports for research development. Brief scenarios 
illustrating efforts underway at several schools depict challenging and often rewarding research capacity building endeavors. This paper presents the perspective of several Deans and Directors in the development of administrative research supports. The paper also features one model for a supportive research administration structure in the pre- and post-award environment.

Vision and mission driven work are the hallmarks of the scenarios reported in this article. External fund generation, absent a strategic vision for impact and alignment with school goals and with demonstrable contributions, would not be successful (Slaughter \& Leslie, 1997). Seeking grants and amassing external funds for their own sake or to secure a profit niche of sorts for the unit would not be desirable. Mission drift, less attention to the educational program and to service would eventuate. Instead the scenarios presented here identify ways in which the research enterprise advances the mission of the school, university, and diverse community partners.

Social work schools and departments often have to advance on the research front expeditiously. Research intensive universities may downgrade or close non-productive units. The stakes are high for social work programs and their futures. Teaching universities also expect more scholarship and research productivity from faculty. Given high teaching loads, such expectations may be more modest but are nonetheless used as one benchmark to document the overall profile of both individual faculty and the unit collectively.

There is growing uncertainty about academic budgets in higher education. This is particularly pronounced in public universities that are often experiencing declines in state support. Thus, the enhanced research portfolio becomes increasingly used as a 
supplemental funding source for faculty course buy-outs and indirect cost returns to the unit. In addition, external funds for research are often used as a measure of the productivity of the department or school.

In the fifteen years since the first NIMH-funded centers in social work, developments in research among schools include a growing National Institutes of Health (NIH) portfolio (IASWR, 2007). Moreover, it is estimated that the number of schools generating \$3 million in research funds has increased dramatically over the past eight years. An estimated 80 schools and departments have at least one research center. Such accomplishments are the product of much inventive work by faculty and the administrative research supports Deans and Directors have been able to marshal. To achieve such successes, key barriers have been confronted and overcome.

\section{Barriers and Opportunities in Building Capacity for Developing a Research Infrastructure}

A significant barrier for many is the limited research infrastructure in their institution and social work education department or school. Many institutions do not have staff support to assist faculty in preparing grant applications. In some colleges and universities a central institutional faculty grants office, staffed by one or two individuals, serves the whole university faculty consisting of several hundred persons. Many schools and departments confront insufficient organizational support and resources, including the absence of funds for pilot studies, staff, match and technical support, course releases, financial incentives, research assistantships, conference travel, computer software, mentorship, ongoing research consultation and research collaboration with community agencies. 
The return to the academic school or department of indirect cost recovery funds (the overhead charged by the university on grants) often proves challenging. Some institutions may siphon off indirect funds for university support returning only a small percentage to the school or department. Additionally, the approved institutional indirect rate may be so low as to not provide sufficient funds to cover overhead.

Teaching loads and service obligations may have a negative effect on faculty research. Moreover, faculty who bring a preference for teaching must be supported to enhance or acquire more research skills. Addressing this situation presents a multiple challenges: 1) to effect a change in their preferences, 2) to advance professional development, and 3) to provide mentoring, coaching, administrative, fiscal and scientific supports.

Some faculty may be more inclined to engage in research and seek external funding when engaged with others such as in an established research center. Lacking such research center access, there is a void in other mechanisms that might foster more collaboration between those schools with research infrastructures and schools interested in developing their research capacity. Similarly other disciplines, such as medicine, pharmacy, dentistry, economics, and psychology, that may have considerable experience with federally-funded research, are not always eager to partner or may reject partnership overtures.

Given these and many other predictable barriers, it may seem paradoxical that some schools increasingly are able to celebrate successes. Success has come in part because of resources and policies already in place, a "whatever it takes ethic", faculty buy in, and investment that effective leaders can generate. 


\section{Strategic Partnerships: From Entrepreneurial Scholars to Building the Collective}

Many school or departmental cultures in the past have been characterized as a collection of entrepreneurial, autonomous scholars and researchers. Now, the expectation, if not the mandate, to foster research infrastructures and capacities requires much more collaboration within the school and across disciplines. Moving from solo scholar-entrepreneurs to collective teams of researchers requires numerous strategies and supports. The first may involve the hiring of faculty with interests that intersect with the emerging research priorities of the faculty as a whole. A critical mass of faculty may be needed as scientific endeavors are increasingly a collective enterprise. Such collaborative research cultures support the emergence of centers, institutes, and school- agency research collaborations.

Strategic partnerships can advance the research enterprise as Deans and Directors with key faculty work with philanthropic foundations on their investment priorities or partner with a state or county office on research projects or on the development of a center. Such partnerships are reinforced by pressures to advance evidence-based practices (EBP) when the evidentiary base may be limited. In other cases there may be an attempt to adapt evidence-based approaches from one service sector to another, such as from juvenile justice to child welfare requiring rigorous testing of promising practices.

The breadth of the social work profession positions schools and departments to advance improved outcomes for the poor, immigrants, and other diverse underserved groups, children and families, elderly and those with mental heath, health impairments, addictions or disabilities. As faculty members specialize-in one of these areas, their 
talents can be aligned with appropriate public and private sector funders to advance new research and evaluation.

Partnership strategies vary. They may include meetings initiated by the dean or director with interested parties (Commissioners, foundations, community agency leaders, other department and schools) about the collaboration potential, followed by meetings with key faculty and related agency staff. In other cases broader dialogue with all interested faculty across multiple disciplines to explore mutual research interests may be in order. In this instance a meeting may be facilitated between all the children's researchers across a university with a Commissioner of Child Welfare. The social work school or department is seen as a conduit for collaboration but not pressed to deliver all the research expertise and faculty contributions. Such collaboration can expand the opportunities for faculty to do more interdisciplinary research.

Partnerships may also span and integrate parts of the research and educational enterprise. This integration may create the educational program and additional scholarship opportunities through increased focus on educational assessment. Educational outcomes assessment and improvement charting are core facets of a research infused school and department. Field education programs may develop field units that serve as incubators of practice and policy pilots, or promising and potentially evidence- based practices.

Faculty Development and Support: Mentoring and Coaching Programs 
To advance scholarship and research in this new more collaborative culture two kinds of faculty mentoring systems are appropriate. One involves tenure-related mentoring and the other scientific mentoring. While collegial mentoring by more senior faculty may help untenured faculty with strategic decision-making about where to publish, on manuscript development and advancing related scholarship priorities, scientific mentors faculty or hired consultants from another discipline or university. Such scientific mentors are particularly helpful to the faculty researcher who is seeking an NIH grant. The scientific mentor may provide guidance about promising grants opportunities, serve as a co- PI, help with conceptual, methodological, statistical designs and analyses as well as research subject access. Coaching may also be a significant part of the development process and include helping a faculty member prepare a grant proposal, steward a relationship with a grants officer, and tailor research interests to the funder's needs and priorities.

The link between tenure and research grants also demands more from faculty than in the past. Scholarship productivity increasingly may include funded research. Moreover, in several universities, emerging criteria for tenure may include funded grants from NIH for faculty in social work. To offset such pressures, in more than one university, an NIH grant submission may warrant a year off the clock toward tenure.

In many cases, as research funds grow and opportunities outstrip faculty capacity or interest, the development of new faculty positions may be warranted. For example, research associate and post-doctoral positions may be created. In some schools, research assistant, associate and full professor lines are created with grant funding behind these positions. 
Funds to support faculty in their grant procurement is of utmost concern to Deans and Directors. Funds may be needed for pilot research (seed grants), often essential for faculty hoping to move forward as NIH investigators, stipends for grant writing, course buy outs, and technical assistance with grant applications (NADD, 1997). Sometimes the Vice President for Research will invest in these infrastructure supports (a grants manager, pilot funds, and stipends for grant writing).

\section{Inclusive Research: A Model From the School of Social Work, University of Texas, Austin}

Research centers play a key role in infrastructure development. NIH-funded research Centers (NIMH and NIDA infrastructure grants in 14 schools) have helped document the need and benefits of additional mechanisms and administrative supports for research.

We begin our snapshots of schools and departments by profiling briefly one of the Centers enhanced with the NIDA funded infrastructure grant at the University of Texas at Austin. This mission driven Center for Social Work Research provides 1) grant information, 2) faculty assistance with proposals involving literature reviews, form preparation, budget development, IRB approval process and proposal routing through the university system, along with secretarial supports, accounting, and 3) faculty incentives to engage in research (White \& McRoy, 2005). A research center can also steward funding supports so that as one grant ends, staff can be transitioned to another ensuring both sustainability of staff and the intellectual and scientific capital that has been accumulated. Much discerning work involves matching faculty and funding (White \& McRoy, 2005). The University of Texas School of Social Work has long held the 
reputation of being a research-oriented unit. Its history reveals early involvement in research activities, primarily focused on state level program evaluations, but also an early record of federally funded research by some scholars. Presently, every faculty member has some level of research funding.

Such an enviable accomplishment is the by-product of its Research Center, the strategic work of the Dean and Associate Dean for Research and other stakeholders such as the Vice-President for Research. The University of Texas Austin School of Social Work is one that now has a research portfolio of over $\$ 22$ million. Like others, it began with modest grants. Such capacity development and success may take a decade or more to establish. An increase in the number of faculty positions in the School of Social Work has accompanied this increase in research productivity.

The School has also established an institute structure as a means to allow faculty members with particular field of practice interest to collaborate around research and practice interests. At the time of this writing, there are seven (7) institutes that are focused on specific practice areas. Organizationally, the institutes fall under the umbrella of the Center for Social Work Research. Utilizing various faculty strengths and interests through these units has encouraged broader faculty participation and commitment in research activities.

Research infrastructures may also compel the appointment of an Associate Dean for Research. In this post the incumbent will discern faculty interest and talents, matching grant opportunities with interests. Associate Deans for Research also may foster interdisciplinary research and outreach scholarship involving diverse populations. Much 
of the work of this Associate Dean includes stewarding the grant submission process and managing the staffing supports.

We turn now to a School that had three Centers as a foundation but doubled them and placed them under an umbrella Institute. These Centers and the supports developed dovetail with the simultaneous school goal of submitting \$3 million in research grants each year

\section{The National Catholic School of Social Service (NCSSS) at The Catholic University of America (CUA)}

In 2002, three research centers existed within NCSSS that focused on aging, child and family services, and international social development. However, the Centers on Aging and International Social Development primarily offered education and training in the form of certificate programs either to graduate students or professionals in the local community. The Child and Family Services Center had secured a number of small contracts related to program evaluation within local non-profit social service agencies. Although these projects produced a number of published papers and conference presentations, the funds available within these agencies for program evaluation were not always adequate to cover all of the school's costs. In addition, indirect costs were often not covered.

In 2004, a faculty retreat was conducted to present, critique and revise a proposed research agenda structure for the school. First, research was to become the primary mission of each center with education and training assuming a secondary role. Second, three new centers were recommended by the Dean based upon a national review of research activities in other schools of social work in collaboration with the faculty as well as an analysis of critical issues such as the specific levels of expertise within the school as 
well as needs within the local community. The three centers that were proposed and established were Community Development and Social Justice, Health and Mental Health, and Spirituality and Social Work.

The mission of these Research Centers of NCSSS is to continue to pursue studies relevant to "evidence-based practice" whenever possible. Most often, it is the intent for pilot studies to lead to the testing of interventions in six critical areas pertinent to social work practice for the next decade. Also, graduate students at the MSW and doctoral level can be actively be integrated in the execution of these studies through research assistantships.

The initial goals for the NCSSS' research centers were to: 1) unite faculty in the pursuit of EBP-related research in six areas pertinent to the profession and NCSSS; 2) enroll every full-time faculty member in one or more Centers; 3 )provide resources to faculty to assure successful grant applications to organizations such as NIH and relevant private foundations; 4)link graduate students with faculty investigators through graduate assistantships; 5) submit grant applications with a total request of \$3M; 6) survey field agencies for potential partners; 7)increase the development of manuscripts for peerreviewed journals through Center writing groups; 8) promote research outcomes within CUA as well as external sources such as local, regional, national, and international conferences.

Negotiations with the NIH enabled CUA to complete an Interagency Personnel Agreement that allowed the former Deputy Director of the NIDA to join the staff of NCSSS to advise on the development and implementation of a research agenda and related infrastructure. Since 2004 this advisor has provided significant guidance in the 
mission of the research centers, their structure, and potential ideas for specific grant applications. In this role, he also has initiated a number of web resources related to grant writing and sources of funding on a school-wide shared drive.

Within a year later, all full-time faculty had committed to serve as a member for one or two centers, Directors and Associate Directors were named for each center, and monthly meetings were initiated for each center. One outcome of these early efforts was the formation of writing groups within each center to begin the development of manuscripts based on existing databases. By 2006, three major grants were developed and submitted. Although these applications were not funded, a research culture is slowly emerging within the school with hopes of submitting $\$ 3$ million in grant applications. Over the past four years, the 19 full-time faculty of NCSSS have published 2 textbooks, 3 monographs, 13 book chapters, and 61 peer-reviewed journal articles, and presented over 150 papers at local, regional, national, and international conferences. Recently, a proposal has been presented to a potential donor for a gift of $\$ 3$ million to create NCSSS' Institute for Social Work Research that would serve as the overarching infrastructure for the six individual research centers. Within the Institute, resources such as research assistants (NCSSS graduate students), interviewers, and possibly a biostatistician would be available to each of the six centers. In this way, resources will be available as needed, and significant duplication of resources across centers can be avoided.

The significant lesson learned over the past three years is that the development of a research culture is a slow and tedious process. The essential key is the open and honest dialogue between a dean and faculty that directly addresses fears, frustrations, and revisions associated with the overall plan to generate significant change. Each semester, a 
day-long retreat is held off campus, and progress in the development of these centers is part of each retreat. On occasion, the entire retreat has been devoted to research, and in addition, the Dean holds an "all center director meeting" each semester. This format provides the opportunity for problem identification and resolution in relation to issues that affect all of the six centers.

Our next brief profile of the Wayne State University School of Social Work developments involves the simultaneous building of a Ph.D. program, a Center and administrative research supports for faculty. Like the Catholic University and University of Texas snapshots, these developments took a number of years. Infrastructures evolve and develop in non-linear fashions. As research profiles and faculty cultures advance, new opportunities, needs, and barriers develop.

\section{Parallel Processes in Research Capacity Building: Beginning Steps at the Wayne State University School of Social Work}

The Wayne State University School of Social Work's journey comprised parallel steps over a 7-year period. These steps involved developing a culture to support an ambitious, collective research and scholarly vision; strategic hiring of administrative leadership, support staff and talented faculty members; securing buy-in of faculty, communicating these ambitions and securing support from central administration and the communities of potential donors and community collaborators; building research capacity and establishing a Ph.D. program. These efforts culminated in the establishment of a Center for Social Work Research, offering collaborative research opportunities with agency partners, technical assistance and professional development.

The School's goal was to become as central to the University's strategic research mission as it is to its teaching and service mission. To this end, a research director was 
hired in the school with a strong record of research funding involving urban research problems. Developing research capacity required an "organizational will" to expend energy on strategic planning, building faculty buy-in on research and publication goals, communicating the School's achievements and goals to central administration, starting a Ph.D. program and building a research infrastructure. Research goals included increasing scholarly productivity and helping new, untenured faculty members to develop a focused research agenda along with aiding all faculty members with pre-award and post-award supports. Capacity-building also required an organizational culture that provided other tangible supports for research and publication.

The School reduced faculty teaching load after gaining approval from the Provost (from a $3 / 2$ teaching load to a $2 / 2$ teaching load with reduced loads for early career faculty). Other investments included 1) increased conference travel budget support for scholarly papers leading to more publications, 2) increased travel budgets to support faculty attendance at workshops on grant proposal development, 3) summer support of faculty as well as competitive summer research and publication funding for up to two years, 4) research and publication mentors assigned to tenure-track faculty members to assist with internal and external grant proposals, determining a research focus, and establishing a publication plan.

The School, since then, has hired a Research Coordinator to support the work of the Research Director, who provides methodological support to faculty and assists with pre and post-award activities. In addition the school has provided internal funding for three to four graduate research assistants, assigned to the School's research office, to respond to faculty requests for research assistance. Special training has built the capacity 
of the School's business manager to provide accounting services for faculty grants and to maintain "shadow accounts."

With dedicated funds, particularly from indirect cost returns, services are provided by statistical consultants, grant writers, and methodological consultants. In addition, there has been as expansion and upgrading of the School's applied research and training facility to include 30 computer workstations, state-of-the-art equipment and software for qualitative and quantitative data analysis. A part-time manuscript editor has been hired to assist faculty with editing publications and grant proposals. In addition, secretarial staff have been trained to help prepare grant proposals and to submit governmental proposals online.

The School embarked upon a parallel four-year process that culminated in the establishment of the Ph.D. program and a Research Center. A needs assessment resoundingly supported the need for the Research Center and delineated community needs. In addition, the dean and center director visited potential donors to support the Center and met with more than five large community-based organizations to secure their commitment to serve as research and training partners. To date, four of these agencies have agreed to collaborate with the School to link their needs with faculty research, and seek external funding for research, training and projects to alleviate problems faced by client systems. Moreover, the Provost has approved the School's request to use funds from a variety of sources (gifts, indirect cost returns, savings and the General Fund Account) to serve as seed money for the Center. Simultaneously, the School has established an internal center advisory group and is carefully forming an external advisory group. 
The parallel processes of change and capacity building depicted in the last two vignettes underscore how transformational much of the work can be. New centers, Ph.D. programs, workload changes, and heightened research expectations along with new staff in support of these may all seem ambitious, and for some, more than is feasible. We use another example that builds upon the IV-E funds for training in child welfare as is depicts ways to move from child welfare training to a more diversified, research, training, and technical assistance infrastructure.

\section{Getting Started: Leveraging IV-E Funds}

Increasing numbers of schools and departments may have a Child Welfare Institute or Center. Such Institutes or Centers may focus on training, education, service delivery and research support for child welfare practitioners (child protection workers, foster parents, and related professionals). Child Welfare Institutes and Center Directors work with high level policy officials in local and state Child Welfare Departments as well as other key public and private sector collaborators. While such Institutes and Centers provide extensive training opportunities, they also generate other opportunities for external funding, particularly funds that support research agendas. The strong ties that develop over the years around training and education agendas can also help launch joint research endeavors.

Using a somewhat similar federal match strategy as with IV-E, several schools are using Medicaid partnerships to bring in research funds. However, Medicaid partnerships are more slowly developing (Behrman, Mancini et al., 2005). Unlike the more narrow focus of IV-E funds pertaining to foster care, Medicaid funds have a more encompassing scope as they are to improve outcomes for Medicaid eligible populations, including 
impoverished children, parents and elders. We cite next an example in which IV-E and related supports were mobilized to create a regional center at the Department of Social Work at California State University, Fresno. Moreover, unlike other examples in this paper, this Center is led by Director of the Department.

\section{The Central California Social Welfare, Evaluation, Research and Training Center (SWERT) at California State University, Fresno}

The Department of Social Work Education in an effort to support the mission of California State University Fresno, and its College of Health and Human Services' goal of becoming an engaged regional institution began its journey of becoming an "engaged Department" in 2003-04. The Department was a recipient of a university grant which supported civic engagement activities. The Department's efforts to reach out to and engage the community led to the recognition of the regional nature of many issues facing California's Central Valley. From this, the Central California Social Welfare, Evaluation, Research and Training Center (SWERT) was formally recognized as an Ancillary Unit in 2005 at the Department of Social Work at California State University, Fresno. It serves as an umbrella for Title IV-E Education and Training, Specialized Foster Parent Training, a quality assurance claims process, and internships with new efforts focusing on social work related training, evaluation, and research. The Center is a collaborative effort between the Department of Social Work Education, the Regional Training Academy, community agencies, Directors of social services agencies, and other university partners. The Center provides a venue for faculty to seek external funding. The opportunities and benefits presented by the SWERT are intended to support and enhance scholarly research, provide program and outcome evaluation for community partners, enhance 
collaboration, augment educational experiences for students, and develop data that will assist and inform the practice community in the region. All faculty were extended an invitation to become involved in the development and planning of the center.

As grants are acquired they provide support for the Center's evaluation, research, and training activities. These resources will be utilized to further the engagement agenda, to foster collaboration among faculty, other university departments and centers, and community partners.

Much research infrastructure development has involved centers and partnerships in support of their success. Of equal importance is the integrity in fiscal management, internal to the school. We feature now the role of a research administrator who advances individual as well as collective faculty grant endeavors.

\section{Research Administration: University of Illinois at Urbana-Champaign School of Social Work}

Most discussions of the development of research infrastructures in schools of social work focus on helping faculty develop the knowledge and skills needed to submit competitive grant applications to major funders, especially NIH. Research administration - the structure and administrative supports for submitting and operating grants- is critical to any successful infrastructure developments.

The university office of grants and contracts is responsible for submission of grants, distribution of funds and accountability for expenditures. That office typically reports to a vice chancellor for research. In addition, a separate office may steward funds for corporations and foundations. With grant procurement comes a major fiduciary responsibility that needs to be managed in the school or department. 
The Illinois experience suggests the need for institutionalizing supports for the development of grants ("pre-award") and for the implementation of grants ("post-award") within the social work program. A sufficiently large grant operation will require separate people carrying out these functions. At the University of Illinois, pre-award responsibilities are managed by the Research Administrator who is also the Director of Budget and Planning who reports directly to the Dean. The Research Administrator meets with potential PIs, reviews the program announcement related to the specific grant, assists in the development of the budget and budget justification, and serves as the intermediary with the university grants office. With electronic submission of grants, the Research Administrator assists faculty in the process.

The Research Administrator needs to be someone, typically with a master's degree in business or public administration, who has experience in grant development, budget development, and understands and interprets university and funder policies to faculty PIs. This administrator needs to be able to advise the Dean on the business side of research infrastructure, understand how grants further the mission of the school, and participate actively in the school's leadership team.

At the University of Illinois School of Social Work, the Research Administrator supervises a business manager who is responsible for post-award duties. Depending on the number and size of grants, other staff may be needed to assist the business manager. A primary responsibility is preparing regular expenditure reports for the PI to review, assisting the PI in understanding that report, and making adjustments in expenditures as needed. Other duties include the purchasing of materials for grants, hiring staff, handling of travel and payments to research participants. 
The research administrator's primary task involves the facilitation of research in the school or department (SRA International, 2007). Two professional societies represent the interests of research administrators and further their career development: SRA International and the National Council of University Research Administrators (NCURA, 2007). SRA International includes research administrators from a wide variety of settings including industry, government, and universities. NCURA serves primarily university research administrators. NCURA's Statement of Principles (2007) address roles and responsibilities of research administrators, faculty professional and academic and intercultural property rights, and their need to be apprised of regulations, policies and procedures which affect the conduct of their research programs. Such principles also underscore the importance of the Research Administrator's stewardship of external funds supporting research and scholarship, attention to conflicts of interest and oversight of the health and safety aspects of research programs. Thus, recognition that this research administration warrants a professional, essential to the expanding research enterprise, will be beneficial to both the social work program and to the Dean and Director.

\section{Implications}

These selected examples of work underway compromise a beginning and very selective inventory of some of the ways in which schools and departments have developed research portfolios and infrastructures. They do not examine the downside of the research enterprise. For example, in some cases faculty buyouts from teaching may place too many adjunct faculty in the class room and change the nature of the educational experience of students (McCurty \& McClelland, 1997). Despite these and many other caveats, the work that lies ahead is the simultaneous development of research and 
administrative infrastructures in which the school mission is aligned with rather than impeded by the research enterprise. Moreover, the evidence based movement and mandates engulfing helping professions and state and federal agencies as well as voluntary partners compel new intervention research that has been often less pronounced even in the most robust research environment.

Infrastructure development goes hand in hand with faculty supports and cultures that nurture research. New cultures, reward systems and intensive supports to launch successful research grants require inventive practices by the Dean and Director and the faculty. Each school and department becomes a learning community. To date the mechanisms for charting this inventive process have been limited. The need for a national clearinghouse and innovation exchange is pronounced. One step in this direction is the Institute for the Advancement of Social Work Research. The St. Louis Group, whose members are Deans and Directors with $\$ 3$ million or more in research, also serves as another vehicle for such exchange. This special issue of the Journal of Social Work Research comprises yet another vehicle for information sharing. Ultimately, the reintroduced National Center for Social Work Research, through Congress, might further such goals and ensure that these developmental lessons and journeys can be more systematically chronicled, synthesized and disseminated.

Innovation exchange involving the regionalization of some of our research infrastructure supports with other schools and departments may also enhance impact and responsiveness to community needs. Smaller programs may have access to populations that larger research schools require. Smaller schools and departments may benefit from the collaboration because of infrastructure access and collective impact. In some cases, 
the school with the most infrastructure could serve as a hub for multi site and even multi state research.

$\mathrm{NIH}$ investments in social work research have affirmed the contributions of our profession to the scientific enterprise addressing some of the most pressing problems in our communities. Some of these investments have been mirrored by those of the John A. Hartford Foundation in the Faculty Scholars and Doctoral Fellows Programs. Our schools and departments have shown that they are worthy investment sites for the development of quality research. In turn the research reculturing has been nothing short of transformative in many of our schools and departments.

\section{REFERENCES}

Behrman,G; Mancini,M;Briar-Lawson,K;Rizzo, V.M.;Valentine,C; (2006).Exploring strategies to advance public-sector funding in geriatric social work education. Journal of Social Work Education,42(1)37-38 (Winter).

Institute for the Advancement of Social Work Research, 2007. IASWR develops directory of funded research, retrieved, September 15,2007 from http://www.iaswrresearch.org/

McCurty \& McClelland, 1997).Trends in student-faculty ratios and the use of non-tenure track faculty in MSW programs. Journal of Social Work Education,33, 293-306

NCURA (2007). Statement of principles. http://www.ncura.edu/content/about_us/statement_of_principles.php. Downloaded 9-20$\underline{07}$.

National Association of Deans and Directors of Schools of Social Work, 1997, Challenges and opportunities for promoting federally funded research in social work programs, The Task Force on Administrative Research Infrastructures in Social Work Programs, Washington DC 
SRA (2007). What is a research administrator?

http://www.sraintrenational.org/sra03/template/tntbAB.cfm?cid=37\&id=692.

Downloaded 9-20-07.

Slaughter,S \& Leslie,L,L, 1997 Academic capitalism: Politics,policies and the entrepreneurial university. Baltimore: John Hopkins University Press

White,B. \& McRoy,R, (2005). Research infrastructure models, NADD Research plenary, (September 17th), San Antonio, Texas 